\title{
Structural Alterations in the Rat Kidney After Acute Arsine Exposure
}

\author{
Felix Ayala-Fierro, Ann Linda Baldwin, Lisa May Wilson, Jan Edward Valeski, and \\ Dean Edwin Carter
}

\author{
Departments of Pharmacology and Toxicology (FA-F, DEC) and Physiology (ALB, LMW, JEV), Colleges of Pharmacy \\ and Medicine, The Center for Toxicology, University of Arizona, Tucson, Arizona
}

\begin{abstract}
SUMMARY: The mechanism of arsine $\left(\mathrm{AsH}_{3}\right)$ toxicity is not completely understood. In this investigation, the toxicity of $\mathrm{AsH}_{3}$ and $\mathrm{AsH}_{3}$-produced hemolytic products was determined in primary culture of renal cortical epithelial cells and in the in situ isolated rat kidney. The objective of this study was to model kidney dysfunction caused by $\mathrm{AsH}_{3}$ exposure. The hypothesis was that unchanged $\mathrm{AsH}_{3}$ and $\mathrm{AsH}_{3}$-produced hemolysate that may contain arsenite (As(III)) as metabolite are both responsible for renal toxicity. Toxicity in isolated cells was determined by 2, 3-bis[2-methoxy-4-nitro-5-sulfophenyl]-2H-tetrazolium-5-carboxanilide inner salt (XTT) bioreduction, intracellular potassium $\left(\mathrm{K}^{+}\right)$, and lactate dehydrogenase (LDH) leakage. Data from XTT bioreduction showed that most toxicity occurred at 1 hour and was independent of the arsenic species. At 4 hours, the observed toxicity depended on the arsenic species and was generated by As(III). In the isolated cells, the As(III)-spiked hemolysate produced similar toxicities with regard to intracellular $\mathrm{K}^{+}$and $\mathrm{LDH}$. The $\mathrm{AsH}_{3}$-hemolysate only affected $\mathrm{LDH}$ at 1 hour. Unchanged $\mathrm{AsH}_{3}$ was very toxic to the isolated rat kidney. In this system, after 10 minutes exposure to $\mathrm{AsH}_{3}$, the effects of toxicity were observed mainly in the glomerular and peritubular endothelial cells. Tubular epithelial cells also presented early signs of toxicity. The $\mathrm{AsH}_{3}$-hemolysate was not toxic after a 10-minute exposure. These data suggested that early cytotoxicity caused by unchanged $\mathrm{AsH}_{3}$ results in kidney dysfunction, produced by $\mathrm{AsH}_{3}$, and later by the formation of a hemolysate that may contain $\mathrm{As}(\mathrm{III})$. These data may be important in understanding the renal toxic effects after $\mathrm{AsH}_{3}$ intoxication. (Lab Invest 2000, 80:87-97).
\end{abstract}

A rsine gas $\left(\mathrm{AsH}_{3}\right)$ is the most acutely toxic form of arsenic (threshold limit value $=50 \mathrm{ppb}$, ACGIH 1982) with hemolytic toxic action that can be fatal. $\mathrm{AsH}_{3}$ is used extensively for epitaxial growth of gallium arsenide and as a dopant for silicon-based electronic devices in the semiconductor industry. Human exposure to $\mathrm{AsH}_{3}$ can occur from accidental release of the gas during these manufacturing processes or from accidental generation from arsenic-contaminated substances, such as wastes from mining and manufacturing, paint, and herbicides (reviewed by Buchanan, 1962). The first clinical symptom in humans who have been exposed to $\mathrm{AsH}_{3}$ is intravascular hemolysis with dark red urine (hematuria). This is followed by abdominal pain, jaundice, and anemia; the latter is caused by massive hemolysis. Laboratory results demonstrate hemoglobin concentrations of $<10 \mathrm{~g} / 100 \mathrm{ml}$, intravascular erythrocyte fragments, ghost cells, anisocytosis and poikilocytosis, reticulocytosis, and a plasma hemoglobin of $>2 \mathrm{~g} / 100 \mathrm{ml}$. Exposure to $\mathrm{AsH}_{3}$ is reportedly fatal in up to $25 \%$ of the human cases that have been studied (Fowler and

Received October 11, 1999.

This study was supported by National Institute of Environmental Health Sciences Grant ES06644

Address reprint requests to: Dr. F. Ayala-Fierro, Department of Pharmacology and Toxicology, College of Pharmacy, Room 248A, University of Arizona, Tucson, Arizona 85721. Fax: 520-626-2466. E-mail: ayala@ pharmacy.arizona.edu
Weissberg, 1974), and death is usually caused by acute oliguric renal failure.

The mechanism of $\mathrm{AsH}_{3}$ hemolysis is not clearly understood. Previous studies have proposed oxidant and nonoxidant mechanisms of toxicity. Pernis and Magistretti (1960) postulated that $\mathrm{AsH}_{3}$ exerts its toxic effects through oxidative stress depleting glutathione; however, recent investigators (Hatlelid et al, 1995) contradicted that earlier finding. Other authors have suggested that $\mathrm{AsH}_{3}$ reacts with key sulfhydryl groups of the membrane sodium $\left(\mathrm{Na}^{+}\right)$, potassium $\left(\mathrm{K}^{+}\right)$ATPase pump (the main mechanism for volume control), inducing cell swelling and lysis (Levinsky et al, 1970). Recent investigations showed that $\mathrm{AsH}_{3}$ was toxic to dog erythrocytes (which do not have $\mathrm{Na}^{+}$, $\mathrm{K}^{+}$-ATPase pump) (Hatlelid et al, 1995). In addition, $\mathrm{AsH}_{3}$ did not significantly alter ATP levels or inhibit the ATPase in human erythrocytes (Winski et al, 1997).

Acute oliguric renal failure is the complication that most often results in death (Fowler and Weissberg, 1974). It is unclear whether $\mathrm{AsH}_{3}$ cytotoxicity in organs other than blood is caused by unchanged $\mathrm{AsH}_{3}$ or whether conversion to a metabolite, possibly associated with hemolysis products (eg, AsIII), is required. This study was conducted using primary cultures of rat kidney cortical epithelial cells, and the in situ isolated rat kidney, to model kidney toxicity caused by $\mathrm{AsH}_{3}$ and $\mathrm{AsH}_{3}$-produced hemolytic products, and to determine whether conversion of $\mathrm{AsH}_{3}$ to arsenite (As(III)) is necessary for toxicity. $\mathrm{K}^{+}$leakage (an indicator of early cell toxicity), lactate dehydrogenase 
$(\mathrm{LDH})$ release (an indicator of cell death), and bioreduction of 2, 3-bis[2-methoxy-4-nitro-5-sulfophenyl]2H-tetrazolium-5-carboxanilide inner salt (XTT) (mitochondrial marker) were used as the cytotoxic parameters to assess damage to the epithelial cells. Toxicity for the in situ isolated kidney was assessed by observing ultrathin tissue sections by electron microscopy. The renal cortical epithelial cells were more susceptible to $\mathrm{As}$ (III) than to $\mathrm{AsH}_{3}$-hemolytic products. In the in situ isolated kidney, $\mathrm{AsH}_{3}$ was toxic to the endothelial cells from glomerular and peritubular microvessels. Proximal tubular epithelial cells presented early signs of toxicity. The $\mathrm{AsH}_{3}$-hemolysate was not toxic in this system over the short time period of application.

\section{Results}

\section{Effect of Hemolysates on Bioreduction of XTT}

The $\mathrm{AsH}_{3}$-hemolysate and the As(III)-spiked hemolysate produced significant toxicity during the first hour and were not significantly different from each other (Figure 1). At 2-hour incubation, $\mathrm{AsH}_{3}$-hemolysateincubated cells started to recover, whereas As(III)spiked hemolysate and $\mathrm{AsH}_{3}+\mathrm{As}$ (III)-hemolysate produced a stronger toxicity compared with 1-hour incubation (Figure 1). At 4-hour incubation, $\mathrm{AsH}_{3}-$ hemolysate-treated cells recovered completely from toxicity. As(III)-spiked hemolysate and $\mathrm{AsH}_{3}+\mathrm{As}(\mathrm{III})-$ hemolysate-treated cells started to recover from toxicity. At this time point, the biggest difference was found between the $\mathrm{AsH}_{3}$-hemolysate and the As(III)hemolysate-treated cells (Figure 1). At 6-hour incubation, almost all groups were completely recovered

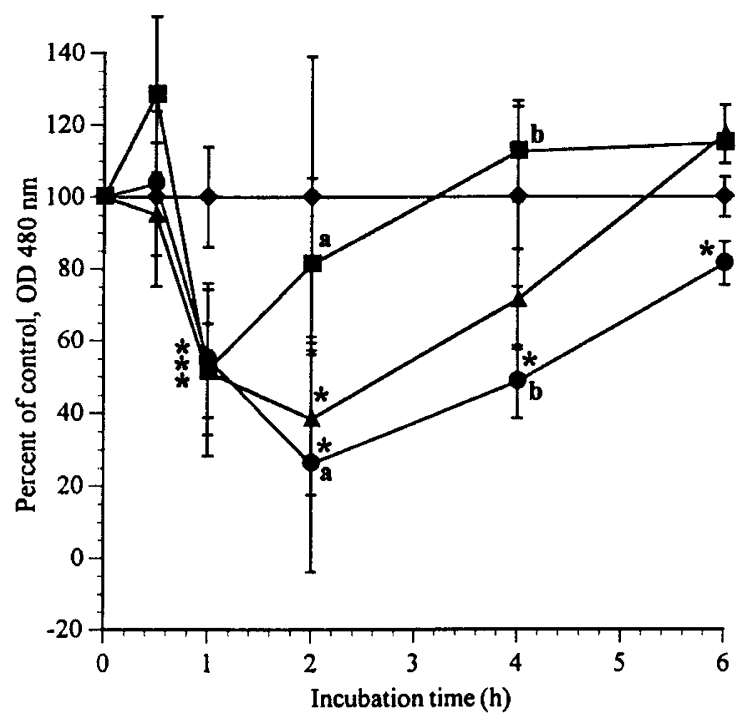

Figure 1.

Bioreduction of XTT in renal cortical epithelial cells exposed to control

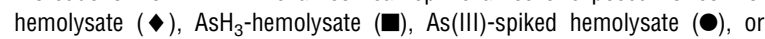

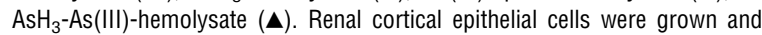
dosed with each hemolysate for $0.5,1,2,4$, and 6 hours as described in Materials and Methods. Values are mean $\pm \mathrm{SD}(n=3)$. Asterisks denote values significantly different from control; letters $a$ or $b$ denote treatment values significantly different between them $(p<0.05)$. $O D$, optical density. from toxicity (Figure 1), and at 24 hours, no toxicity was found (data not shown). Based on these data, two time points were chosen to further investigate the toxicity of arsenical-hemolysates: (a) the time of no difference in toxicity (1 hour); and (b) the time of the greatest difference (4 hours) between $\mathrm{AsH}_{3}-$ hemolysate and $\mathrm{As}(\mathrm{III})$-spiked-hemolysate toxicity.

The soluble and insoluble hemolytic fractions were prepared as described in Materials and Methods. Rat renal cortical epithelial cells were dosed with these two hemolytic fractions for 1 or 4 hours. The soluble fraction was found to be most toxic. At 1 hour, the $\mathrm{AsH}_{3}$ hemolysate soluble fraction was not toxic, but the soluble fractions from $\mathrm{As}$ (III) and $\mathrm{AsH}_{3}+\mathrm{As}(\mathrm{III})$ hemolysates were toxic (Figure 2). At 4 hours, the soluble fractions from all treatment groups were very toxic, with the As(III)-fraction being the most toxic species (Figure 2). The insoluble fractions from any group presented no toxicity at 1 hour. At 4 hours, the insoluble fractions from all groups, except the $\mathrm{AsH}_{3}$ hemolysate-soluble fraction, were toxic (Figure 2). The effect of these two arsenicals, prepared in 50:50 phosphate-buffered saline (PBS):media (1 mM), presented no toxicity at 1 hour, and only As(III) presented some toxicity at 4 hours (data not shown). These latter results may suggest that there is little contribution of the hemolysate products to toxicity, and hence, that toxicity is due to the presence of the arsenicals.

\section{Effect of Hemolysates on Intracellular Potassium and Lactate Dehydrogenase}

Intracellular $\mathrm{K}^{+}$leakage is used as an early sign of toxicity and indicates loss of cellular control over ion

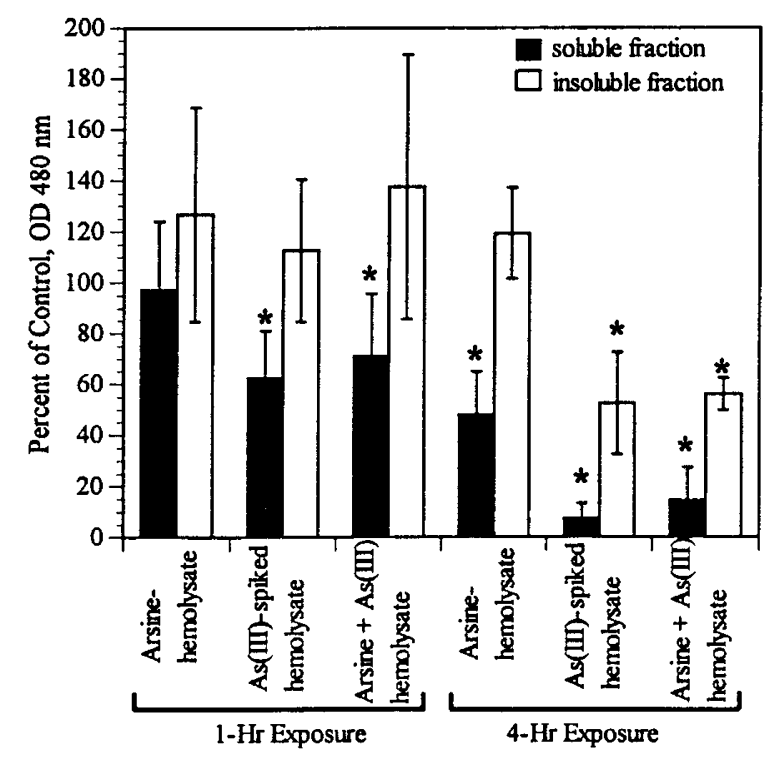

Figure 2.

Bioreduction of XTT in renal cortical epithelial cells exposed to the soluble and insoluble fractions from control hemolysate, $\mathrm{AsH}_{3}$-hemolysate, As(III)-spiked hemolysate, or $\mathrm{AsH}_{3}-\mathrm{As}$ (III)-hemolysate. Renal cortical epithelial cells were grown and dosed for 1 and 4 hours as described in Materials and Methods. Values are mean \pm SD $(n=3)$. Asterisks denote values significantly different from control $(p<0.05)$. 
fluxes. LDH release occurs only when cells have ruptured, and is indicative of cell death. Renal cortical epithelial cells were grown in T-25. Once treated with the soluble and insoluble fractions from the arsenicalhemolysate, the cells were rinsed carefully to determine intracellular LDH and potassium. Data are reported as percent of control. Intracellular $\mathrm{K}^{+}$was only affected by the soluble hemolytic fractions from the As(III)-spiked hemolysate (Figure 3A). Neither soluble nor insoluble fractions from $\mathrm{AsH}_{3}$-hemolysate were toxic (Figure 3A). Intracellular LDH was decreased only by the soluble fraction from both groups at 1 hour. At 4 hours, $\mathrm{AsH}_{3}$ hemolysate (either fraction) had no effect, but As(III)-hemolysate (both fractions) produced toxicity (Figure 3B).

\section{Effect of $\mathrm{AsH}_{3}$ and $\mathrm{AsH}_{3}$-Produced Hemolysate in the In Situ Isolated Kidney}

All three control kidneys demonstrated that our perfusion and fixation protocols were successful. They
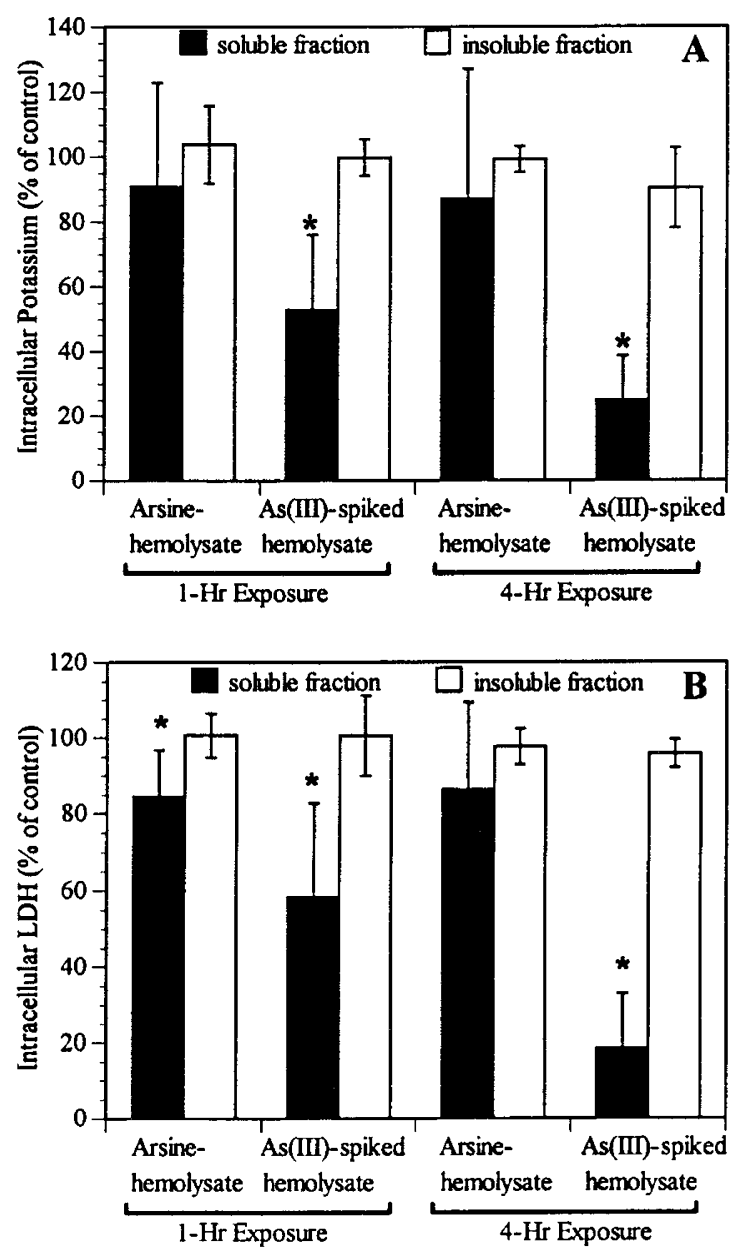

Figure 3.

Leakage of intracellular potassium and LDH in renal cortical epithelial cells exposed to the soluble and insoluble fractions from control hemolysate, $\mathrm{AsH}_{3}$-hemolysate, and $\mathrm{As}(\mathrm{III})$-spiked hemolysate. $A$, Potassium leakage measured as intracellular $\mathrm{K}^{+}$(percent of control). B, LDH release measured as percent of control. Renal cortical epithelial cells were grown and dosed for 1 and 4 hours as described in Materials and Methods. Values are mean \pm SD $(n=3)$. Asterisks denote values significantly different from control $(p<0.05)$. showed glomeruli in good condition with normal basement membrane, normal, unfused epithelium, and normal microvessels with intact, fenestrated endothelium (Figure 4, Control). In control preparations, occasional $10-\mathrm{nm}$ gold particles were observed adhering to the endothelial surface of microvessels, but none were seen in the interstitium, indicating that the microvessels were not damaged. The in situ isolated rat kidneys perfused for 10 minutes with $1 \mathrm{~mm}$ of $\mathrm{AsH}_{3}$ showed the effects of toxicity. At this time frame, the main target for $\mathrm{AsH}_{3}$ toxicity was the fenestrated endothelium of glomerular capillaries and the nonfenestrated endothelium of peritubular arterioles and venules (Figures 5 to 7). In Figure 5 is shown a glomerular venule. The endothelial cells demonstrated cytoplasmic protrusions, and many apparently free islets of cytoplasm. These "islets" were probably joined to the attached endothelium in another plane. At this stage, the basement membrane and glomerular epithelium appeared to be normal. Figure 6 demonstrates a higher magnification micrograph of the endothelium of a glomerular venule. A gap has formed between two endothelial cells, and $10 \mathrm{~nm}$ gold particles were visible in the interstitium. Such gaps were seen in a large proportion of glomerular venules from the $\mathrm{AsH}_{3}$-treated kidneys. Figure 7 shows a transverse section through an arteriole, identified by the presence of subendothelial smooth muscle cells. The endothelium can be seen uplifted from the basement membrane, and the interstitium is edematous. At this time frame, the tubular epithelial cells had also become damaged, but to a lesser extent (data not shown). The $\mathrm{AsH}_{3}$-produced soluble hemolytic products were not toxic to the perfused kidney (Figure 8). The endothelium was intact, with few cytoplasmic protuberances, and there was little evidence of interstitial edema. No endothelial gaps were observed, and there were no gold particles in the interstitium.

\section{Discussion}

In this study, we investigated the cytotoxicity of $\mathrm{AsH}_{3}$ produced hemolytic products in the in situ perfused rat kidney, and cytotoxicity to primary cortical epithelial cells. The objective of this study was to determine whether the renal toxicity, observed in humans who were exposed to $\mathrm{AsH}_{3}$, was a nondirect effect of $\mathrm{AsH}_{3}$ that required the formation of the hemolysate. It was hypothesized that $\mathrm{As}$ (III) was present in the $\mathrm{AsH}_{3}-$ hemolysate as a product of $\mathrm{AsH}_{3}$ metabolism. Previously, we identified $\mathrm{As}(\mathrm{III})$ and $\mathrm{As}(\mathrm{V})$ as metabolites of $\mathrm{AsH}_{3}$ in rat kidney homogenates (Ayala-Fierro et al, 1999). It is also probable that other arsenic compounds, such as $A s(0)$, are formed. $A s(0)$ has not been analyzed but its presence in aqueous solution was indicated by a precipitate. In this study, we attempted to compare the perfused kidney and renal cells and their responses to $\mathrm{AsH}_{3}, \mathrm{AsH}_{3}$-hemolytic products, with $\mathrm{As}$ (III) to determine whether $\mathrm{AsH}_{3}$ acts directly or after forming a hemolysate containing $\mathrm{As}$ (III).

Our results confirmed that $\mathrm{AsH}_{3}$-hemolysate was toxic to cortical epithelial cells as assessed by the 




\section{Figure 4.}

Electron micrograph of a transverse section through glomerular capillaries of a control in situ perfused kidney. Note the intact endothelium $(E)$, basement membrane $(B M)$ and epithelium $(E P)$. Scale bar $=2 \mu \mathrm{m}$.

mitochondrial marker XTT. Cytotoxicity occurred during the first hour. $\mathrm{AsH}_{3}$-hemolysate-treated cells recovered fast and were recovered completely by 4 hours. The addition of $50 \% \mathrm{As}(\mathrm{III})$ to the $\mathrm{AsH}_{3}$ hemolysate delayed recovery to 6 hours. As(III)spiked-hemolysate treated cells did not completely recover by 6 hours. As(III) seemed to be the toxic species that produced cell death by damaging the cell mitochondria. As(III) might be taken up by the mitochondria where it binds to the thiol groups of important mitochondrial enzymes, including the dehydroge- nase enzyme, responsible for bioreducing XTT. This $\mathrm{AsH}_{3}$-hemolysate had almost no toxic effects on the cells' ability to maintain control over ion fluxes (intracellular $\mathrm{K}^{+}$), or on the cell integrity marker, LDH. These data confirm the findings previously reported (AyalaFierro et al, 1999) for unchanged $\mathrm{AsH}_{3}$. Intracellular $\mathrm{K}^{+}$ and LDH were not changed in rat renal cortical epithelial cells exposed to $1 \mathrm{~mm} \mathrm{AsH}_{3}$ for 1,3 , or 5 hours, but were changed by $1 \mathrm{~mm}$ of $\mathrm{As}$ (III). These cells incubated for 24 hours were damaged at a lower $\mathrm{AsH}_{3}$ concentration (10 $\mu \mathrm{M})$ (Ayala-Fierro et al, 1999). 


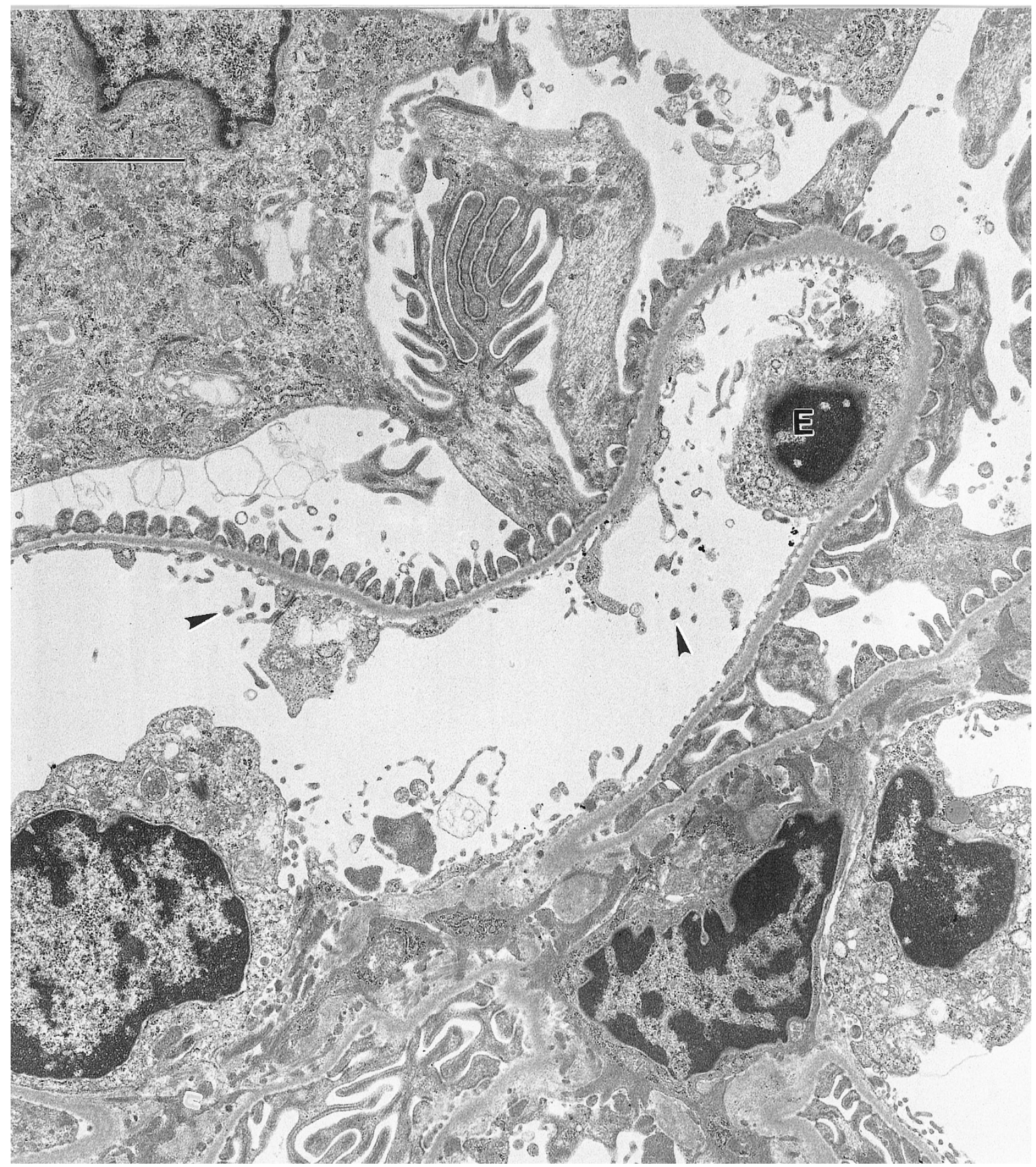

\section{Figure 5.}

$\mathrm{AsH}_{3}$ toxicity in the in situ perfused kidney. Note the endothelial projections and islets (arrowheads) in the glomerular capillary. Scale bar $=2 \mu \mathrm{m}$. $E$, intact endothelium.

In the in situ isolated rat kidney, $\mathrm{AsH}_{3}$ rapidly produced toxicity in the endothelial cells of the glomerular and peritubular microvasculature and caused gaps that allowed the gold particles to escape capillaries and venules and to internalize. The proximal tubular epithelial cells were also affected, but to a lesser extent. The main damage for the epithelial cell was presented at the nucleus. The reason for this is unknown. Due to the short perfusion time, the epithelial cell was not completely damaged. A longer perfusion time would completely demonstrate the epithelial cell as a target for direct $\mathrm{AsH}_{3}$ toxicity. Evidence indicates that the epithelial cell is a target for $\mathrm{AsH}_{3}$ nephrotoxicity. A study on asymptomatic $\mathrm{AsH}_{3}$ nephrotoxicity (Levy et al, 1979) reported the case of an analyst who worked in a platinum metal refinery and who was exposed to $\mathrm{AsH}_{3}$ toxicity twice during a period of a week. Although the analyst was asymptomatic, the death of a coworker in the same industrial area suggested that he had been also exposed. He was checked at 1,2, and 5 weeks after the exposure to $\mathrm{AsH}_{3}$; results indicated that everything was normal 


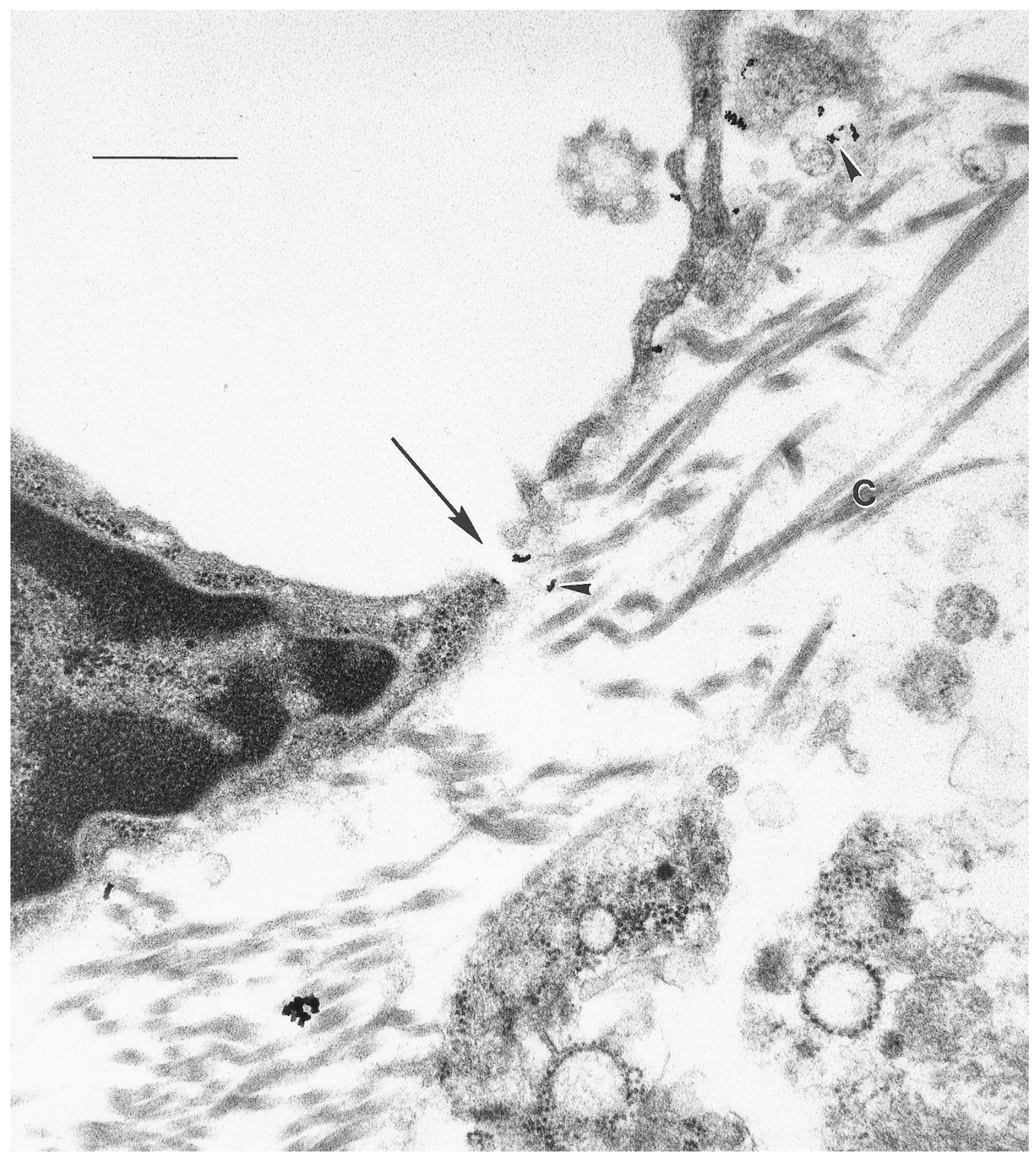

\section{Figure 6.}

$\mathrm{AsH}_{3}$ toxicity in the in situ perfused kidney, showing peritubular capillary. Also shown are an endothelial gap (arrow) and 10-nm gold particles in the interstitium (arrowheads). C, visible collagen fibers. Scale bar $=0.5 \mu \mathrm{m}$.

with no evidence of hemolysis or arsenic in hair specimens. At week 6 after exposure, a renal biopsy specimen was obtained. The main pathologic changes were seen in the proximal tubules. The epithelial cells were swollen and many of the nuclei contained prominent nucleoli. A number of the epithelial cells showed rupture of the cytoplasmic membranes, with liberation of cytoplasmic organelles into the tubular lumens. Within some tubules, the changes had progressed to frank necrosis of the lining cells, with the basement membranes remaining intact and of normal thickness. Some other tubules had characteristics of tubular regeneration. Structural changes at the nuclei were also observed in this study at 10 minutes. Other studies (Ayala-Fierro et al, 1999) have shown that the rat cortical epithelial cells are damaged by direct $\mathrm{AsH}_{3}$ exposure. These cells responded slowly to $1 \mathrm{~mm} \mathrm{AsH}_{3}$ during the first 5 hours, but at 24 hours, they were damaged by $\mathrm{AsH}_{3}$ concentrations of $>10 \mu \mathrm{M}$ (AyalaFierro et al, 1999). These data suggested that the 




\section{Figure 7.}

$\mathrm{AsH}_{3}$ toxicity in the in situ perfused kidney. Also shown is a transverse section through a peritubular arteriole $(A)$. Note the endothelial separation from the basement membrane (arrowhead), and the interstitial edema (Ed). Epithelium (EP) of a loop of Henle is visible. Scale bar $=2 \mu \mathrm{m}$.

proximal cortical epithelial cell is not an immediate target for $\mathrm{AsH}_{3}$ toxicity, but these cells are damaged at a later time.

The soluble hemolytic products produced by $\mathrm{AsH}_{3}$ did not affect the kidney. The insoluble products were removed to allow renal perfusion. It was demonstrated that complete hemolysate cannot be used as the perfusate. Complete hemolysate clogged the kidney in a brief time period of 2 to 5 seconds. The soluble hemolytic fraction was used to test the hypothesis that a metabolite, As(III), was formed in the hemolysate. Due to the short perfusion time, no evidence of toxicity was found. This result does not mean that the perfusate is not toxic, but it may imply that if $\mathrm{As}$ (III) were present in the hemolysate, 10 minutes is not enough time to produce toxicity. Thus, in this time frame, hemolysate toxicity in situ cannot be determined. This time frame was chosen to maintain normal kidney function; however, a longer perfusion time is required to demonstrate whether the soluble hemolytic perfusate is toxic. The soluble hemolytic products were 


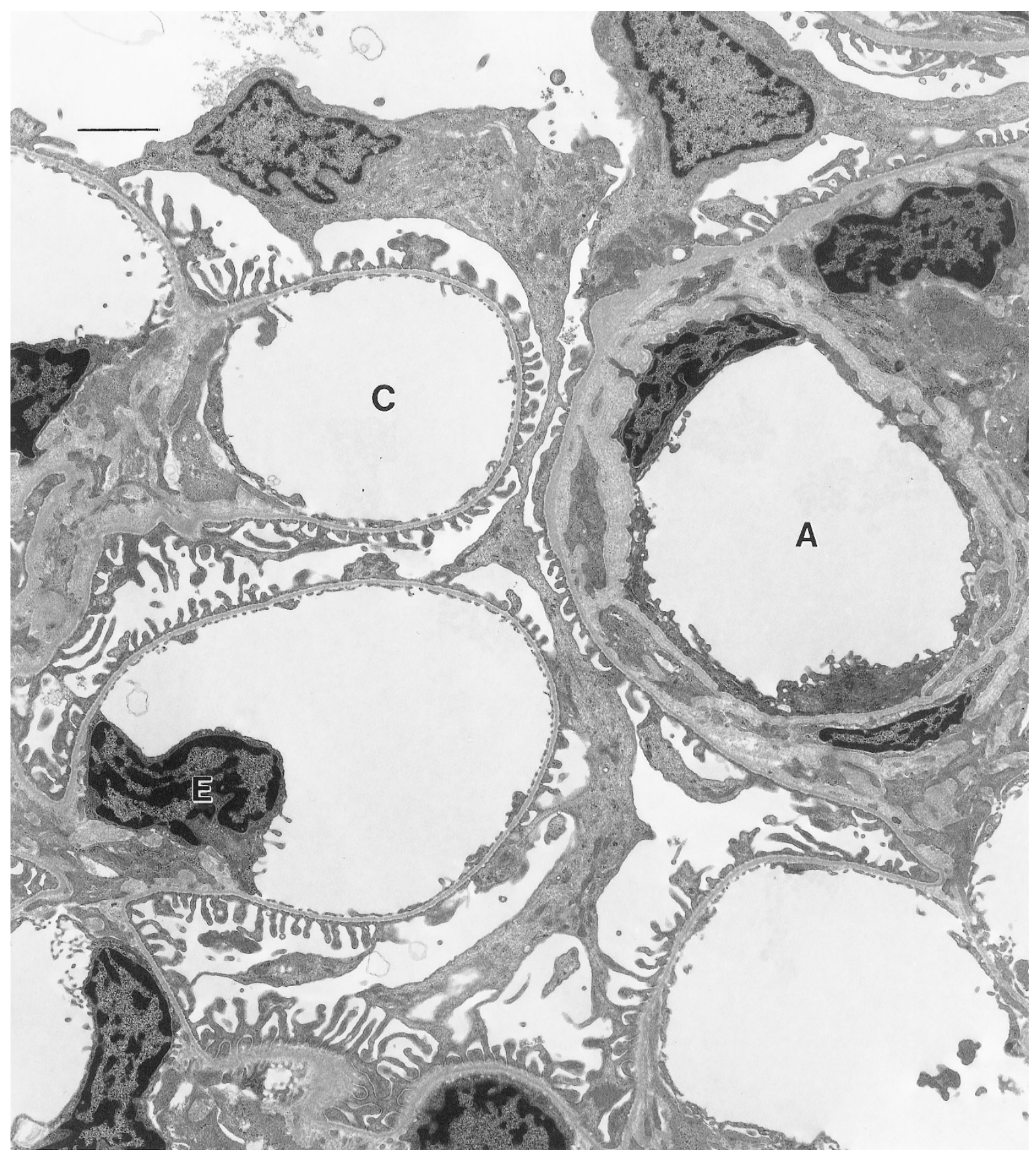

\section{Figure 8.}

$\mathrm{AsH}_{3}$-produced soluble hemolytic products in the in situ perfused kidney, showing a portion of a glomerulus. All structures appear to be normal. $A$, arteriole; $C$, capillary; $E$, endothelium. Scale bar $=2 \mu \mathrm{m}$.

toxic to the isolated renal cortical epithelial cells. These cells may be a target for the hemolysate, but they require a longer exposure time.

We conclude that $\mathrm{AsH}_{3}$ dissolves in plasma and is delivered to the kidney where it produces early toxicity. This renal effect would be dose dependent and would determine the delay period (2 to 24 hours) for the symptoms to appear. The endothelial cells from the glomerular capillaries and peritubular microvessels would be the first to become affected, causing compromised filtration and edema. At subsequent time points, when $\mathrm{AsH}_{3}$ disappears but red blood cells are lysed, the hemolytic products reach the kidney. Insoluble hemolytic products would clog the glomerulus and further compromise filtration. The effect of the $\mathrm{AsH}_{3}$-hemolysate on the mitochondrial marker from the isolated renal epithelial cells, with little effect on intracellular $\mathrm{K}^{+}$and $\mathrm{LDH}$, may indicate the formation of a toxic intermediate (probably an arsine peroxide) at early time points. The insoluble hemolytic product may contain the metabolite and would further damage the tubular epithelial cells that were initially affected by 
unmetabolized $\mathrm{AsH}_{3}$. The combination of all these effects would lead to oliguric renal failure.

In summary, the renal cortical epithelial cells were almost exclusively susceptible to As(III)-spiked cytotoxic effects. $\mathrm{AsH}_{3}$, but not $\mathrm{AsH}_{3}$-produced hemolytic products, was toxic to the in situ perfused rat kidney after a 10-minute perfusion. The effect of $\mathrm{AsH}_{3}$ may result from its conversion, first to a rapidly diffusible compound, and then to As(III); both were delivered through the hemolysate to the kidney.

\section{Materials and Methods}

\section{Chemicals}

Sodium arsenite, American Chemical Society (ACS) certified, was purchased from Fisher Scientific (Fair Lawn, New Jersey). Zinc arsenide, 99\%, and pyridine, ACS grade, were obtained from Aldrich Chemical Company (Milwaukee, Wisconsin). D-MEM/F-12 (Dulbecco's Modified Eagle Medium supplemented with Factor 12) powder medium was purchased from Gibco/BRL Products (Grand Island, New York). Fetal bovine serum was obtained from Gemini Bioproducts, Inc. (Calabasas, California). T-25 culture flasks were obtained from Becton-Dickinson (Indianapolis, Indiana). XTT (2, 3-bis[2-methoxy-4-nitro-5-sulfophenyl]$2 \mathrm{H}$-tetrazolium-5-carboxanilide inner salt), phenazine methosulfate, and all other chemicals were purchased from Sigma Chemical Company (St. Louis, Missouri). Phosphate-buffered Karnovsky's fixative contained $2 \%$ formaldehyde and $2.5 \%$ glutaraldehyde (Electron Microscopy Sciences, Fort Washington, Pennsylvania). Sodium cadodylate $(0.15 \mathrm{M}$ of sodium cadodylate buffer) and 10-nm gold colloid (5.7 $\times 10^{12}$ particles/ $\mathrm{ml}$ ) were purchased from Ted Pella, Inc. (Redding, California).

\section{Animals}

Male Sprague Dawley rats, weighing 250 to $350 \mathrm{gm}$, were purchased from Harlan Sprague Dawley, Inc. (Indianapolis, Indiana) and acclimated for 7 days before use. Rats were allocated randomly to groups ( $n=$ 3) such that the groups' mean values and standard deviations in body weight were approximately equal. A standard laboratory diet and water were provided to all animals ad libitum. A 12-hour on, 12-hour off light cycle was maintained in the animal room. The temperature and relative humidity were maintained at $22^{\circ} \mathrm{C}$ and approximately $40 \%$, respectively.

\section{Arsine Generation}

$\mathrm{AsH}_{3}$ was generated by the method of Hatlelid et al (1995). Zinc arsenide was reacted with $50 \%$ sulfuric acid to generate the $\mathrm{AsH}_{3}$ gas, which was bubbled into serum-free D-MEM/F-12 medium to the desired concentration. $\mathrm{AsH}_{3}$ concentration was determined by reaction with $0.55 \%$ diethyldithiocarbamate in pyridine followed by spectrophotometric determination of this product at $510 \mathrm{~nm}$. Caution: $\mathrm{AsH}_{3}$ is a toxic gas and appropriate precautions should be taken. All pro- cedures should be performed in an approved fume hood. A saturated potassium permanganate solution trap, in-line after the aqueous trap, should be used to prevent the release of $\mathrm{AsH}_{3}$ during its generation.

\section{Isolation and Dosing of Rat Renal Cortical Epithelial Cells}

Renal cortical epithelial cells were isolated by the method of Ayala-Fierro et al, (1999). Cell incubations were performed at $37^{\circ} \mathrm{C}$ and $95: 5 \% \mathrm{O}_{2} / \mathrm{CO}_{2}$ with saturated humidity in a humidified incubator (Model 6300, National Appliance Company, Portland, Oregon) at $37^{\circ} \mathrm{C}$ and $5 \% \mathrm{CO}_{2}$. Before exposure to the hemolysate, the attached cells were adapted to serum-free D-MEM/ F-12 medium, $2 \mathrm{ml}$ per flask, for 2 hours. Then, this medium was removed and the cells were dosed with the appropriate hemolysate prepared in the serum-free medium. Rat blood sample was collected and packed red blood cells were obtained as described by Ayala-Fierro et al (1999). Packed red blood cells were treated 1:1 with PBS or double distilled water. The dd.-water-treated cells were completely lysed at 30-minute incubation at $37^{\circ} \mathrm{C}$. Control hemolysate was obtained after adding cell growth medium (50\% final concentration) to the water-lysed cells, to restore $\mathrm{pH}$ and osmolarity of the solution. The $\mathrm{AsH}_{3}$-produced hemolysate was obtained by treating PBS-red blood cells 1:1 with $2 \mathrm{~mm}$ of $\mathrm{AsH}_{3}$ prepared in cell growth medium and incubated for 30 minutes at $37^{\circ} \mathrm{C}$. The As(III)-spiked hemolysate was obtained after adding 1:12 mM As(III) prepared in cellgrowth medium to the water-lysed cells. The $\mathrm{AsH}_{3}$ and As(III) final concentration was $1 \mathrm{~mm}$ in $25 \%$ packed red blood cells and $50 \%$ cell-growth medium. Soluble hemolytic products were prepared by filtering hemolysates through 0.2-CA syringe filters (Pall Gelman Laboratory, Covina, California). Insoluble hemolytic products were resuspended in an equal volume of 1:1 PBS:cell- growth medium. Cell incubations were performed at $37^{\circ} \mathrm{C}$ and 95:5\% $\mathrm{O}_{2} / \mathrm{CO}_{2}$ with saturated humidity in the incubator.

\section{Bioreduction of XTT}

$\mathrm{XTT}$ bioreduction was performed, as described by Divine et al (1999), with slight modification. The cells were enzymatically harvested from the rat kidneys and $8 \times 10^{3}$ cells $/ 200 \mu$ l were seeded per well in 96 well plates in D-MEM/F-12 medium supplemented with $5 \%$ fetal bovine serum and $50 \mu \mathrm{g} / \mathrm{ml}$ of gentamicin. The cells were allowed to recover from isolation by incubating them for 24 hours at $37^{\circ} \mathrm{C}$ and $5 \% \mathrm{CO}_{2}$. The next day, the serum-containing medium was removed completely and $200 \mu \mathrm{l} /$ well of the serum-free medium was added. The plates were incubated for 2 hours at $37^{\circ} \mathrm{C}$ and $5 \% \mathrm{CO}_{2}$ to enable adaptation to the new conditions. During this time, all the hemolysates were prepared in the serum-free medium; 200 $\mu \mathrm{l} /$ well was added after removing the adaptation medium. The plates were incubated for $0.5,1,2,4$, and 6 hours at incubation conditions described above. After incubation, the hemolysate was removed and the cells-containing wells were washed carefully with ster- 
ilized PBS until all hemolytic products were completely removed. Cell viability was determined by XTT that was prepared as described by Divine et al (1999) and added $200 \mu \mathrm{l} /$ well. XTT, in combination with phenazine methosulfate (electron-coupling agent), was metabolized by mitochondrial dehydrogenase enzymes of metabolically active cells (Roehm et al, 1991). The resultant chromogen formed was proportional to the amount of cells remaining alive. The plates were incubated for 4 hours with the dye agent and then read at $480 \mathrm{~nm}$, using a plate reader (Dynatech MR5000, Chantilly, Virginia) that was linked to a computer program (Biolinx 2.20, Dynatech Laboratories, Inc., Chantilly, Virginia).

\section{Determination of Intracellular Potassium and Lactate Dehydrogenase}

Potassium and LDH were determined in cell lysate (intracellular). After dosing, the cells were washed with Tris- $\mathrm{HCl}$ buffer $(\mathrm{pH}$ 7.4) at least three times or until all blood products were removed completely from the wells or flask wall (required three to five washes). Then, the cells were scraped and sonicated (AyalaFierro et al, 1999). Intracellular potassium was determined by flame photometry and intracellular LDH was determined (kit LDL-228, Sigma Chemical Company).

\section{In Situ Isolation and Perfusion of the Rat Kidney}

Five male Sprague-Dawley rats, weighing 250 to 350 $\mathrm{gm}$, were anesthetized with pentobarbital sodium (6 $\mathrm{mg} / 100$ body weight ip). In each rat, after tracheotomy for ventilation, a midline incision was made and the left renal artery was cannulated in the direction of blood flow, and perfused with $3 \mathrm{ml}$ of HEPES-buffered saline (HBS, pH 7.4), containing 1 unit/ml of heparin, at $37^{\circ} \mathrm{C}$. Next, the abdominal aorta was cannulated distal to (downstream to) the right renal artery in a retrograde fashion, and clamped distal to the superior mesenteric artery. The free end of the catheter tubing was connected to a reservoir with HBS that could be pressurized to allow for perfusion, and thus, to assure that cannulation had been successful. Next, the vena was ligated proximal to the renal veins to prevent increased venous pressure in the kidneys, and the rat was euthanized with a mixture of pentobarbital and phenytoin (Beuthanasia). Then, the renal veins were incised so that they would act as outlets. The right kidney (control) was flushed to remove blood and perfused with D-MEM/F-12 medium for 10 minutes, followed by perfusion with HBS to clear the kidney of any remaining medium. The test kidney (left) was perfused with $1 \mathrm{~mm}$ of $\mathrm{AsH}_{3}$ prepared in D-MEM/F-12 medium or with the arsine-hemolysate soluble fraction. Perfusion was maintained for 10 minutes followed by perfusion with HBS. Thus, in each rat, one kidney was the control and the other kidney was used for testing toxicity. The control and test kidneys were switched in the subsequent experiment (left to right, and right to left, respectively). After HBS perfusion, both kidneys were perfused with a $10 \mathrm{~nm}$-gold parti- cles colloid (Ted Pella, Inc., Chicago, Illinois) in 0.9\% $\mathrm{NaCl}$. Finally, the kidneys were perfused with Karnovsky's fixative in phosphate buffer, $\mathrm{pH} 7.4$, at $4^{\circ} \mathrm{C}$. When the perfusion was complete, the renal veins were clamped and fixation continued for 60 minutes; fixative was also applied to the outside of the kidneys. After fixation, each kidney was excised and cut into several segments, each about $0.5 \mathrm{~cm}$ long, including the renal cortex, inner medulla, and outer medulla. These segments were washed in buffered saline and processed (see next section). A total of three control kidneys, three perfused with $\mathrm{AsH}_{3}$, and three perfused with the $\mathrm{AsH}_{3}$-hemolysate soluble fraction, were obtained for pathologic evaluation.

\section{Tissue Preparation for Electron Microscopy}

Tissue segments were immersed in sodium cadodylate buffer overnight. Then, tissues were postfixed in $1 \%$ osmium tetroxide for 2 hours, dehydrated in alcohols, embedded in Spurrs resin, and sectioned for electron microscopy. Grids were stained with uranyl acetate and lead citrate.

\section{Data Analysis}

Individual experiments were performed at least in duplicate, and sample number ( $n$ ) refers to the number of at least three separate experiments. All data are expressed as the mean \pm standard deviation (SD). Statistical analyses were calculated with one-way analysis of variance (ANOVA), using Bonferroni's multiple comparison test (GraphPad Prism, GraphPad Software, Inc., San Diego, California), and Student's $t$ test; two samples assuming equal variances (Microsoft Excel 7.0 statistical package) were used, where required. Values are denoted with an asterisk $\left(^{*}\right)$ when they were statistically different from controls $(p<0.05)$. Treatment values sharing a common letter $(\mathrm{a}, \mathrm{b}$, or $\mathrm{c})$ are significantly different from each other $(p<0.05)$.

\section{References}

American Conference of Governmental Industrial Hygienists (1982). TLV's: Threshold Limit Value for Chemical Substances in Work Air Adopted by ACGIH for 1982.

Ayala-Fierro F, Barber DS, Rael LT, and Carter DE (1999). In vitro tissue specificity for arsine and arsenite toxicity in the rat. Tox Sci 52:122-129.

Buchanan WD (1962). Toxicity of arsenic compounds. In: Elsevier monographs on toxic agents. Amsterdam: Elsevier, 66-102.

Divine KK, Ayala-Fierro F, Barber DS, and Carter DE (1999). Glutathione, albumin, cysteine, and cys-gly effects on toxicity and accumulation of mercuric chloride in LLC-PK 1 cells. $J$ Toxicol Environ Health 57:489-505.

Fowler BA and Weissberg JB (1974). Arsine poisoning. N Engl J Med 291:1171-1174.

Hatlelid KM, Brailsford C, and Carter DE (1995). An in vitro model for arsine toxicity using isolated red blood cells. Fundam Appl Toxicol 25:302-306. 
Levinsky WJ, Smalley RV, Hillyer PN, and Shindler RL (1970). Arsine hemolysis. Arch Environ Health 20:436-440.

Levy H, Lewin JR, Ninin DT, Schneider HR, and Milne FJ (1979). Asymptomatic arsine nephrotoxicity. S Afr Med J 56:192-194.

Pernis B and Magistretti M (1960). A study of the mechanism of acute hemolytic anemia from arsine. Med Lavaro 51:37-41.

Roehm NW, Rodgers GH, Hafield SM, and Glasebrook AL (1991). An improved colorimetric assay for cell proliferation and viability utilizing the tetrazolium salt XTT. J Immunol Methods 142:257-265.
Winski SL, Barber DS, Rael LT, and Carter DE (1997). Sequence of toxic events in arsine induced hemolysis in vitro: Implications for the mechanism of toxicity in human erythrocytes. Fundam Appl Toxicol 38:123-128. 